\title{
DRIVERS AND CONSEQUENCES OF BUSINESS-REFERENCE-CONTENT (BRC): THE ROLE OF NARRATIVE TRANSPORTATION IN B2B COMMUNICATION
}

\author{
Chang Mo JUNG $\mathbb{1}^{*}$ \\ School of Business Administration, Yonsei University, Seoul, Korea \\ Received 10 October 2020; accepted 21 June 2021
}

\begin{abstract}
COVID-19 is bringing changes in B2B sales and marketing strategies. Digital interaction with potential customers has become more critical. Business-reference content (BRC) is the most shared content, mainly using narrative format, available to potential customers through digital touchpoints. Reducing perceived purchasing risk has been recognized as the primary benefit of using BRC, but empirical research on this has been insufficient. Therefore, this research investigated the underlying mechanisms of $\mathrm{BRC}$ and related processes that lower risk perception based on narrative transportation theory. For empirical analysis, a serial-parallel mediating model was established in which BRC type (narrative versus non-narrative) influences purchase intention through the mediation of narrative transportation and perceived purchase risks - functional risk and financial risk. In this experimental study, an online survey was conducted in which 233 purchasing managers in Korean companies participated. The analysis confirmed that the BRC type had a significant effect on the level of receivers' narrative transportation. In addition, serial-parallel mediating effects through narrative transportation (primary mediator) and perceived functional risk and perceived financial risk (secondary mediators) were all significant. This research provides meaningful implications in that it broadens the theoretical understanding of BRC by presenting the integrated BRC effect model. Also, it clarifies the importance of narrative BRC in B2B marketing practices.
\end{abstract}

Keywords: B2B content marketing, business-reference content, B2B digital-marketing, narrative content, narrative transportation, B2B purchase risk.

JEL Classification: M41, C83, L20.

\section{Introduction}

Fast innovation in information and communication technology (ICT) has created new ways for individuals and businesses to search for, acquire, and use information (Lamberton \& Stephen, 2016). Above all, in a situation where face-to-face interactions are limited due to COVID-19, digital interaction has become 2-3 times more critical for B2B suppliers (Harrison et al., 2020). These dramatic changes are drawing attention to the importance of mar-

*Corresponding author. E-mail: 2011313041@yonsei.ac.kr

Copyright (c) 2021 The Author(s). Published by Vilnius Gediminas Technical University

This is an Open Access article distributed under the terms of the Creative Commons Attribution License (http://creativecommons. org/licenses/by/4.0/), which permits unrestricted use, distribution, and reproduction in any medium, provided the original author and source are credited. 
keting activities that narratively transport potential customers (Van Laer et al., 2019). The increase in using narrative contents is also found in $\mathrm{B} 2 \mathrm{~B}$ marketing.

Business-reference content (BRC) is the most shared content, mainly using narrative format, available to potential customers through digital touchpoints (Bonnin \& Alfonso, 2019). $\mathrm{BRC}$ can be defined as using existing customers as referrals to attract new customers or build a reputation (Morgado, 2020). The main difference between BRC and general portfolio is that B2B suppliers actively and strategically use existing customers' referrals in marketing activities (Jaakkola \& Aarikka-Stenroos, 2019). BRC types are divided into non-narrative type (e.g., "reference lists") and narrative type (e.g., "success story") (Salminen \& Möller, 2006). Prior researches also called BRC "customer referencing" or "customer-reference marketing" (Jaakkola \& Aarikka-Stenroos, 2019). They are very similar in that it is the marketing content of B2B suppliers that use existing customers as a referrer to influence potential customers' purchase decision.

The primary purpose of $\mathrm{B} 2 \mathrm{~B}$ suppliers using $\mathrm{BRC}$ is to lower the perceived purchase risks of potential customers (Morgado, 2020). B2B buying involves a high level of purchase risks (Brown et al., 2011; Paluch \& Wunderlich, 2016). Because the product is complex, the customer's level of customization is high, and the purchase amount is significant. Moreover, since tangible product characteristics and intangible service characteristics are often integrated, it is difficult to compare B2B products objectively, and the uncertainty is high (Sharma, 2020). Previous scholars suggested that functional risk and financial risk are the core dimension of B2B purchase risk (Paluch \& Wunderlich, 2016). Functional risk refers to the risk that the purchased product could not provide the promised benefits, and financial risk refers to the net monetary loss that accompanies product purchase. These two purchase risks are called economic risk (Brown et al., 2007, 2011).

$\mathrm{BRC}$ can reduce the perceived purchase risks of potential customers (Jaakkola \& AarikkaStenroos, 2019). Because BRC provides indirect learning opportunities to potential buyers by delivering successful purchasing experiences of existing customers. According to social cognition theory (SCT), indirect learning changes an individual's attitudes, beliefs, and behaviors (Bandura, 1986). In particular, narrative content such as a success story promotes social cognition by enhancing the receiver's mentalizing and empathy (Mumper \& Gerrig, 2017).

Scholars went beyond SCT and argued that the persuasive effect of narrative is caused by narrative transportation (Green \& Brock, 2000). Narrative transportation refers to the state of being "placed into and immersed in the world of a narrative" (Van Laer et al., 2019). Narrative transportation changes attitudes, perceptions, and behaviors by eliciting the receivers' positive cognitive and emotional responses to the narrative (Green \& Fitzgerald, 2017). Green and Brock (2000) suggested that transportation stories mentally affect people, reducing their counterarguing motivation. So, narrative transportation theory can explain the reason why narrative $\mathrm{BRC}$ types such as success stories are more commonly used in $\mathrm{B} 2 \mathrm{~B}$ transactions with high purchasing risks (Ruokolainen \& Aarikka-Stenroos, 2016).

Earlier, Jalkala, and Salmienen (2010) argued that academic knowledge lags behind B2B industry practices due to the lack of BRC research. Previous researchers remain at the level of establishing the concept and type of marketing communication using BRC or qualitatively clarifying influence on the inside and outside of the organization (Jaakkola \& Aarikka- 
Stenroos, 2019; Terho \& Jalkara, 2017). Morgado (2020) also pointed out that we are still lack of firm understanding of the effect of BRC on the purchasing behavior of potential customers.

A recent empirical study showed the effect of narrative transportation on the executives' perception of a supplier (Anaza et al., 2020); however, as far as the author knows, there is no empirical research on how BRC and narrative transportation lower B2B purchase risks. Considering that the core benefit of BRC is to lower perceived purchase risk (Jaakkola \& Aarikka-Stenroos, 2019), there is a high need for research on this.

Therefore, this study presents a theoretical model that explains the effects of BRC's perceived risk reduction and purchase intention enhancement on the basis of narrative transportation theory and conducts an empirical analysis targeting companies' purchasing managers. The purpose of this study is to 1) broaden the theoretical understanding of BRC's persuasive power with narrative transportation theory, and 2) to provide practical insights for B2B marketers to strategically develop BRC.

This study consisted of literature review, research methodology, results of analysis, discussion, and conclusion in order. The current paper focused on the effects of narrative transportation generated by BRC on purchase intention through the mediation of perceived purchase risks.

\section{Literature review}

\subsection{Business-reference content (BRC)}

Business-reference content is defined as "leveraging existing customers and the value delivered to them in the company's marketing activities" (Jalkala \& Salmienen, 2010). Previous studies explained that BRC concretizes and demonstrates complex solutions and provides an indirect experience of previous performance, relationships, technological functionality, and delivered customer values (Jalkala \& Salmienen, 2010).

Potential consumers can in advance understand and learn the supplier's competencies, the relationship-maintenance method, and the purchase results (Kumar et al., 2013). Therefore, it effectively lowers perceived purchase risk in that more information on value-in-use can be obtained from BRC. In the same vein, Anderson, Narus, and Van Rossum (2006) explained that the reference customers' case serves as a value document which provides reliable information on the value of the supplier's product. As such, business references play an essential role in improving reliability by increasing B2B suppliers' perceived competence. At the same time, it decreases buyers' uncertainty and perceived risk (Jaakkola \& AarikkaStenroos, 2019).

In order to maximize the effectiveness of these BRC, the strategic approach of suppliers is necessary. Because it takes much time for suppliers to select referrers that meet potential customers' needs, in particular, it is costlier to find the first reference (Jaakkola \& Aarikka-Stenroos, 2019). On the other hand, potential customers recognize the risk of biased decision-making due to blindly following others' opinions with overly positive information. 
Prior research explained that there are two types of BRC. One is the customer-reference list that focuses on the amount of positive evidence about a supplier, and the other is "value-in-use" stories, such as success stories that emphasize the richness of the evidence (Salminen \& Möller, 2006). Jalkala and Salminen (2010) classified the types of business referencing into relationship level and delivery level. Relationship level refers to a marketing tool which involves displaying the name of the customer, whereby relationships with reputable customers have a higher reference value. On the other hand, the delivery level involves delivering value-creation activities through several solutions referring to individual projects or deliveries that could be used as reference solutions, reference projects, or reference deliveries. Morgado (2020) explained that narrative BRC provides evidence of real business benefits to potential customers in that it involves "a description of the problem faced by the customer, the solution generated by the vendor and the customer's assessment of the outcome or customer value". Therefore, it can be classified that the relationship level is a non-narrative BRC type and the delivery level is a narrative BRC type. In a similar context, Ruokolainen and Aarikka-Stenroos (2016) classified BRC into quantitative references and qualitative references. Quantitative references are customer-reference lists emphasizing the amount of evidence, and qualitative references are descriptive stories introduced to increase understanding of a B2B company's offerings and value-generation potential.

Taken together, BRC can be divided into two types: narrative BRC (e.g., case studies, success stories, top story, white-label stories) and non-narrative BRC (e.g., customer-reference list). The desired outcome of both BRC types is the same, but narrative BRC exists in a much wider variety of forms (Salminen \& Möller, 2006). The reason why BRC is widely used as a persuasive B2B communication tool can be explained with social cognitive theory (SCT) (Bandura, 1986). According to SCT, personal knowledge acquisition is directly influenced by observing others in the context of social interaction, experience, and outside media influence. Thus, individuals observe the behavior of role models they admire, leading them to make inferences and attributions about consequences of behavior (Bandura, 1986).

It should be noted that narrative acts as a trigger to change the attitude and behavior of receivers by promoting social cognition (Mumper \& Gerrig, 2017). Raymond and Medina (2018) explained that narrative promotes social cognition by increasing the receiver's mentalizing and empathy. Mar (2018) pointed out that the reason narrative bolsters social cognition is because social processes and social contents are entertained through the narrative framework. Therefore, narrative BRC could be more effective in promoting social cognition that changes the attitudes, beliefs, and behaviors of potential customers.

Indeed, the most adopted practices of BRC are success stories and case studies in narrative BRC (Jalkala \& Salminen, 2009; Morgado, 2020). Scholars in the field of narrative went beyond the framework of SCT and suggested narrative transportation as a concept that comprehensively explains the cognitive and emotional influences that narrative has on change in attitudes, beliefs, and behaviors (Green \& Brock, 2000).

\subsection{Narrative transportation theory}

Researchers proposed narrative transportation theory to explain the underlying mechanism via which narrative content works (Green \& Brock, 2000; Van Laer et al., 2019). Narrative transportation refers to "when people lose themselves in a story, and their attitudes and in- 
tentions change to reflect that story" (Van Laer et al., 2014). Researchers have summarized the characteristics of narrative transportation as follows:

(1) Narrative transported people may be less likely to disbelieve or counterargue story claims. Thus, narrative influences a receiver's beliefs (Banerjee \& Greene, 2012).

(2) Narratives enable receivers to mimic an experience and act as a powerful means to form attitudes as much as a direct experience (Green \& Brock, 2000).

(3) Transportation creates strong feelings toward story characters. Therefore, receivers identify themselves with a character and are influenced by the character's experiences and beliefs. In other words, narrative transportation promotes empathy for narrative characters and mental simulation of the story plot, making the audience experience a feeling of entering a world evoked by the narrative. As a result, it triggers a change in the receiver's real-world affective and cognitive responses, beliefs, attitudes, and intentions (Van Laer et al., 2014).

Narrative transportation theory clearly suggests narrative's persuasion mechanism. Green and Brock (2000) argued that, unlike elaboration likelihood model (ELM; Cacioppo \& Petty, 1984) and heuristic-systematic model (HSM: Chaiken, 1980), which emphasize the amount of thought and logical consideration, immersion experience into a story leads to persuasion through narrative transportation. Several studies on narrative transportation's persuasive effect have proven that transportation affects attitude, perception, and intention through two pathways: the receiver's cognitive response and emotional response (Banerjee \& Greene, 2012; Feng, 2018).

In the marketing communication, narrative transportation increases as the content adheres to the narrative format. Deighton, Romer, and McQueen (1989) indicated that a higher degree of dramatization in a commercial induces greater immersion and transportation into the commercial. Kim, Ratneshwar, and Thorson (2017) defined the element of narrative advertising as "who, what, where, why, how, and chronology", and they demonstrated that narrative advertising enhances a viewer's narrative transportation compared to non-narrative advertising. Ruokolainen and Aarikka-Stenroos (2016) showed in a qualitative study on B2B communication that qualitative reference information elements with narrative structure enhance the persuasive power of arguments. Therefore, the authors predicted that there is a difference in the level of a receiver's narrative transportation depending on the BRC type (narrative versus non-narrative).

H1: BRC type has a significant influence on the receiver's narrative transportation.

\subsection{B2B purchase risk}

According to previous studies on BRC, the most critical reason for B2B supplier firms to use BRC is to lower the perceived purchase risk of potential customers (Jaakkola \& AarikkaStenroos, 2019; Kumar et al., 2013). B2B marketing scholars commonly pointed out that functional risk and financial risk are the essential factors in $\mathrm{B} 2 \mathrm{~B}$ purchase risk (Brown et al., 2007; Paluch \& Wunderlich, 2016). This is because B2B purchase risk is determined by the magnitude of the impact of purchase decisions on organizational productivity and profitability. 
Functional risk is a concern that the performance of a product does not meet the customer's expectations. It refers to the risk that a product will not provide the promised benefits, and it is caused by predicting a product's future quality at the time of purchase (Ha, 2002). B2B purchasing has high uncertainty because B2B products are technically advanced and represent a bundle of tangible and intangible attributes Sharma et al. (2020). Moreover, $\mathrm{B} 2 \mathrm{~B}$ products are important for the production process, and the perceived functional risk is evaluated as high in that purchase results can be objectively measured (Brown et al., 2007).

Financial risk relates to the potential loss of money due to the introduction of products (Lippel \& Quinlan, 2011). Financial risk is defined as the net monetary loss and unexpected cost that can occur for the customer, including situations such as product repair, replacement, and refund (Horton, 1976). In addition, the possibility of repeatability of financial losses due to fraud is included in financial risk (Featherman \& Pavlou, 2003). In the B2B context, this means overall loss, i.e., not just loss associated with the product price, but also the occurrence of ongoing maintenance costs incurred after product purchase (e.g., follow-up cost). Therefore, B2B customers make purchasing decisions considering current and future financial burdens.

Some researchers suggested that social risk should be considered a B2B purchase risk (Paluch \& Wunderlich, 2016). However, since B2B purchasing is a group decision-making process, the social risk to individuals may not be significant. If a person is not in charge of purchasing decisions, the impact of social risk could be smaller. Anaza et al. (2020) revealed that the effect of narrative transportation of B2B advertising on "tendency to advocate for the suppliers" is more significant in non-C-level executives than in C-level executives. This means that the social risk of B2B purchase depends on individual differences such as organizational position, role, and responsibility. Considering the above, this study focused on perceived functional risk and perceived financial risk, which are economic risks at the organizational level.

\subsection{Narrative transportation and B2B purchase risk}

According to the perceived risk theory, risk is expressed as the product of "probability of consequences of occurring" and "negative consequence of poor brand choice" (Peter \& Ryan, 1976). In cases where the product is complex, expensive, and infrequently purchased, the uncertainty perceived by the buyer is high (Mitchell, 1992). Thus, B2B purchase carries a high level of perceived risk.

As mentioned earlier, well-organized BRC promotes vivid indirect learning through mental simulation. In addition, as a positive emotional connection and identification with referrers are formed, purchase results are expected to be more positive. As a result, the uncertainty about the purchase result is lowered and then the perceived purchase risk is decreased (Fitzgerald \& Green, 2017). Previous studies demonstrated that highly transported viewers make less critical assessments and reduce counterarguments toward the advertisement and products (Seo et al., 2018). Taken together, narrative transportation could lower the perceived purchase risks.

H2. Narrative transportation will lower perceived functional risk.

H3. Narrative transportation will lower perceived financial risk. 
Scholars explained that narrative transportation changes behavioral intention through changes in a receiver's attitudes and beliefs (Kang et al., 2020). Consumer behavior scholars revealed that narrative transportation influences product evaluation or behavioral intention through changes in a buyer's attitudes or beliefs (Kim et al., 2017). In a study on the effect of story-based microfilm marketing, $\mathrm{Su}, \mathrm{Lu}$, and $\mathrm{Lin}$ (2018) found that narrative transportation using a story plot influences purchase intention through a receiver's affective responses. Escalas, Moore, and Britton (2004) showed that narrative transportation increases positive advertising attitude and brand evaluation by lowering critical thought. In a similar context, Krakow et al. (2018) compared the effects of narrative versus non-narrative advertising and confirmed that narrative advertising lowers negative emotions and counterarguing and raises awareness of completeness, thereby increase purchase intention. By synthesizing the results of previous studies, a multi-mediated path hypothesis was established stating that the BRC type (narrative versus non-narrative) would increase purchase intention through the serialmediation of narrative transportation and potential customers' risk perception (Figure 1).

H4. BRC type influences purchase intention through serial-mediation of narrative transportation and perceived functional risk.

H5. BRC type influences purchase intention through serial-mediation of narrative transportation and perceived financial risk.

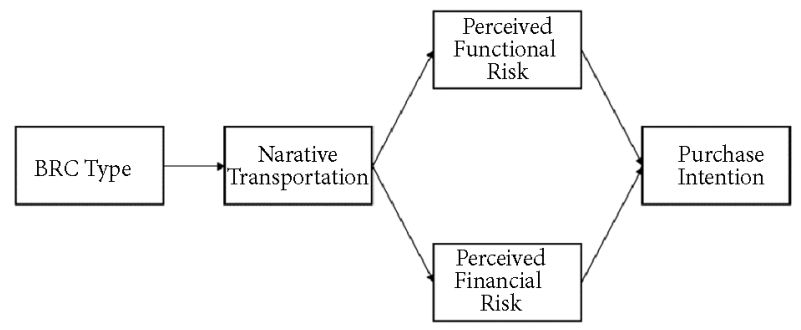

Figure 1. Research model

\section{Research methodology and measurement}

\subsection{Population and sampling}

In this study, an online experiment and survey were used to verify the effect of BRC on narrative transportation, perceived risk dimensions, and purchase intention.

The author conducted a study with Korean employees in occupations related to B2B purchasing. The online survey was conducted by Company M, a survey company that has the largest online marketing panel in Korea. After the survey respondents belonging to the panel completed their own survey, they recommended personnel in the same department and the new respondents joined the online survey by using the URL provided by online survey company (Leiner, 2016). Respondents were given a voucher of 5 USD. Filtering questions were presented to confirm that the respondents are valid samples for the research: 1) "Are you currently in charge of B2B purchasing-related tasks?", "How long have you been in the B2B purchasing task?". If a respondent was not related to the B2B purchasing or understanding of the task was low because he or she does the purchasing task less than one year, they were 
excluded from the sample. A total of 291 respondents participated in the survey, of which 240 met the requirements. Among the collected responses, 233 samples, excluding incomplete responses, were used for analysis (narrative BRC group $=121$, non-narrative BRC group $=112$ ). The sectors that respondents belong to were ICT $31.2 \%$, manufacturing $27.2 \%$, distribution $14.9 \%$, construction $11.1 \%$, and other $15.6 \%$, showing a relatively even distribution by industry. The average length of time respondents was engaged in $\mathrm{B} 2 \mathrm{~B}$ purchasing was 7.3 years. Securing a valid sample is essential in B2B empirical research. This study's sample is judged to be composed of respondents with appropriate experience in B2B purchasing.

\subsection{Stimuli development}

As a product for the experiment, the author prepared "Y-Cloud", a B2B supplier, "Fast-It", a mobile enterprise solution, and "RainFin", a referrer. Stimuli in the study adopted a virtual firm and product to eliminate the effects of existing brand power and the reputation of a particular firm or product. The stimuli for the experiment consisted of a story about the successful introduction of mobile enterprise solution Fast-It by Y-Cloud. The author also considered that a mobile enterprise solution is an augmented product with high technology and intangible service factors. So, perceived purchase risks were expected to be relatively high.

In this study, two BRC types (narrative versus non-narrative) were provided to respondents as stimuli. The author developed narrative BRC with elements of narrative which previous researches commonly emphasized (Gilliam \& Flaherty, 2015). In addition, the author produced a non-narrative BRC stimulus in a format that lists factual information and arguments according to the definition of argumentative advertising (Lien \& Chen, 2013) (see Appendix). BRC presented as stimuli was developed to have the same word and wordoccurrence frequency, so that there was no compounding effect due to other factors besides BRC type. The BRC stimuli was randomly assigned to the respondents.

\subsection{Measurement}

All constructs were measured using multi-item and formative scales. The authors adopted measurement items that had proven reliability and validity in relevant prior studies. 5-point Likert scale was used to measure the items ( 1 - strongly disagree and 5 - strongly agree). The BRC type used as an independent variable was treated as a dummy variable. The stimuli provided in the experiment, narrative $\mathrm{BRC}$ as 1 , and non-narrative $\mathrm{BRC}$ as 0 , were coded and analyzed.

The level of narrative transportation that occurred due to viewers' exposure to the BRC was measured in three items (Green \& Sestir, 2017). The items were "while I was reading the BRC, I could easily picture the events in it taking place", "the events in the BRC are relevant to my everyday life", "I was mentally involved in the BRC while reading it". Perceived purchase risks were measured in the same way. "Perceived functional risk" introduced measurement items used in the study of Grewal, Gotlieb, and Marmorstein (1994): "How confident are you that the product will perform as described?". "How certain are you that the product will work satisfactorily?", and "Do you feel that the product will perform the functions that were described in the BRC". Three items measured "perceived financial risk": "considering 
the potential total cost involved, for you to purchase the product would be risky", "given the potential financial expenses associated with purchasing the product, purchasing the product is associated with overall financial risk", and "I think that the purchase of the product would lead to financial risk for my organization because of the possibility of such things as higher maintenance and/or repair costs" (Grewal et al., 1994). Purchase intention was measured with three items used in the study of Teng, Laroche, and Zhu (2007).

Measurement items went through two rounds of translation (Behling \& Law, 2000). The items were forward translated from English to Korean by a bilingual marketing doctor, and then backward translated from Korean to English by another bilingual marketing doctor without viewing the original items. Then, they compared the original items with the reversetranslated items. Based on the results, removing inconsistencies and differences was made. These double-translated items were verified for the content validity index (CVI $=0.952)$ by five marketing doctoral students focusing on B2B and two marketing professors (Tojib \& Sugianto, 2006). All measurement items developed through these procedures were tested for reliability and validity through the prior exploratory study employing virtual BRC stimuli (Lee et al., 2017).

\section{Results}

\subsection{Reliability and validity}

In this study, the author used lavaan package $0.6-8$ in statistical software $\mathrm{R} 4.0 .4$ and $\mathrm{R}$ studio 1.3.1073 to test the reliability and validity of the measurement items. $\mathrm{R}$ is an open software and is distributed free of charge. In particular, a variety of the latest statistical analysis and data mining functions are continuously provided in a package form, which is highly useful in the field of social science research (Kelly, 2007).

First, confirmatory factor analysis was conducted to verify reliability and validity. The results of testing the goodness-of-fit of measurement model showed good fit $\left(\chi^{2}=96.34\right.$, $\mathrm{df}=48, \mathrm{p}<0.01, \mathrm{CFI}=0.97, \mathrm{GFI}=0.94, \mathrm{AGFI}=0.90, \mathrm{TLI}=0.95, \mathrm{RMSEA}=0.07(95 \%$ $\left.\mathrm{CI}_{\text {low }}=0.05, \mathrm{CI}_{\text {high }}=0.08\right)$ ) (Bagozzi et al., 1998).

Reliability analysis introduced Cronbach's $\alpha$, which is commonly used to confirm internal consistency between measurement items. In social-science research, reliability is assumed to be assured if the a coefficient is higher than 0.7 (Kardes et al., 2019). The Cronbach's $\alpha$ of all factors was found to be higher than 0.7 , so there was enough internal consistency between items. Composite reliability (CR) should also be greater than or equal to 0.7 , and average-variance-extracted (AVE) should be more significant than 0.5 (Bagozzi et al., 1998). All results were above the criteria (Table 1).

Discriminant validity can be measured through a comparison of factor-loading and crossloading. If the factor-loading of the measurement item is higher than the cross-loading, it is estimated that discriminant validity exists. One measurement item must satisfy the condition that the factor-loading for the construct is higher than the factor-loading for the other construct (Hair et al., 2019). If the cross-loading is over 0.4, the factor is considered to be a problem, but the author confirmed that there were no cross-factor coefficients greater than 0.4. Besides, all square roots of the average variance extracted (SQRT_AVE) were higher than 
Table 1. Measurement items and construct evaluation

\begin{tabular}{|c|c|c|c|c|c|c|}
\hline Construct & Items & $\lambda$ & $\mathrm{t}$ & Cronbach's $\alpha$ & $\mathrm{CR}$ & AVE \\
\hline $\begin{array}{l}\text { Narrative } \\
\text { transportation }\end{array}$ & $\begin{array}{l}\text { TRN1 } \\
\text { TRN2 } \\
\text { TRN3 }\end{array}$ & $\begin{array}{l}.906 \\
.934 \\
.878\end{array}$ & $\begin{array}{l}56.458 \\
70.159 \\
39.407\end{array}$ & .887 & .929 & .815 \\
\hline $\begin{array}{l}\text { Perceived } \\
\text { functional risk }\end{array}$ & $\begin{array}{l}\text { FUN1 } \\
\text { FUN2 } \\
\text { FUN3 }\end{array}$ & $\begin{array}{l}.802 \\
.949 \\
.942\end{array}$ & $\begin{array}{l}24.487 \\
95.299 \\
82.239\end{array}$ & .883 & .929 & .812 \\
\hline $\begin{array}{l}\text { Perceived } \\
\text { financial risk }\end{array}$ & $\begin{array}{l}\text { FIN1 } \\
\text { FIN2 } \\
\text { FIN3 }\end{array}$ & $\begin{array}{l}.868 \\
.860 \\
.846\end{array}$ & $\begin{array}{l}44.368 \\
39.168 \\
34.934\end{array}$ & .821 & .894 & .737 \\
\hline $\begin{array}{l}\text { Purchase } \\
\text { intention }\end{array}$ & $\begin{array}{l}\text { PIN1 } \\
\text { PIN2 } \\
\text { PIN3 }\end{array}$ & $\begin{array}{l}.903 \\
.929 \\
.883\end{array}$ & $\begin{array}{l}71.129 \\
91.797 \\
59.906\end{array}$ & .890 & .932 & .819 \\
\hline
\end{tabular}

Note: $\lambda$ : factor loading; CR: composite reliability; AVE: average variance extracted.

the correlation coefficient between the corresponding variable and other potential variables. Therefore, the measurement items were evaluated as having discriminant validity.

In this study, Harman's single-factor test was performed to confirm the common method bias (CMB) (Podsakoff et al., 2012). To this end, exploratory factor analysis was conducted to confirm whether 1) factor with eigenvalue greater than 1 among the unrotated solutions is extracted, and 2) even if a factor with eigenvalue greater than 1 is extracted, whether there is one dominant factor that explain higher than $50 \%$ of the variance of the total variance. As a result of exploratory factor analysis, the number of factors with an eigenvalue higher than 1 was four. In addition, narrative transportation, which accounts for the most explanatory power of variance, was $39.6 \%$, purchase intention $27.7 \%$, financial risk $25.6 \%$, and functional risk $25.7 \%$, so no dominant factor emerged. Also, common method bias will be evident when a large correlation ( $r>0.9$ ) is found among latent variables (Bagozzi et al., 1991), the highest correlation among variables was -0.67 in this study. Therefore, it confirms that CMB was not issue.

\subsection{Hypothesis test}

\subsubsection{Effect of BRC type on narrative transportation}

The author verified whether there is a difference in respondents' narrative transportation according to the BRC type (narrative versus non-narrative). For this, one-way analysis of variance (ANOVA) was performed, and partial eta-squared (partial $\eta^{2}$ ) was used for the effect size of independent variable (Lakens, 2013). R 4.0.4 and sjstats 0.18.1 package were used for the analysis.

The results of ANOVA tests showed that narrative BRC significantly influenced the narrative transportation $\left(\mathrm{F}(1,231)=71.95, \mathrm{p}<0.001\right.$, partial $\left.\eta^{2}=0.246\right)$. This confirmed that respondents who were shown narrative $\mathrm{BRC}(\mathrm{M}=3.482, \mathrm{SD}=0.681)$ experienced the higher narrative transportation than respondents who were shown non-narrative BRC $(\mathrm{M}=2.553$, $\mathrm{SD}=0.499$ ). Thus, $\mathrm{H} 1$ was supported. 


\subsubsection{Test of serial-parallel mediation model}

A serial-parallel mediating model was established to confirm the mediating effect of BRC type to increase purchase intention through narrative transportation and perceived purchase risks. Hayes' Process macro was used for serial-parallel mediating analysis (model 81, 5,000 bootstrapping, 95\% confidence intervals by the percentage method) (Hayes, 2018). Analysis was performed with $\mathrm{R} 4.0 .4$, R studio 1.3 .1073 , lavvan package $0.6-8$, and processR package 0.2.6. PROCESS macro for mediation using bootstrapping has an advantage because it does not assume the normality of the indirect effect distribution and also it confirms that the significance of the indirect effect is not a result of a statistical random error (Hayes, 2018).

First, BRC type, an independent variable, was coded as dummy variable (Narrative $\mathrm{BRC}=1$, non-narrative $\mathrm{BRC}=0$ ). This analysis provides the evaluation of the effect of experimental conditions on purchase intention, a dependent variable, through narrative transportation (primary mediator) and perceived purchase risks (secondary mediators) (Igartua \& Rodríguez-Contreras, 2020). The results showed that BRC type significantly increased narrative transportation $(\mathrm{b}=0.709, \mathrm{SE}=0.086, \mathrm{p}<0.001)$, and significantly lowered perceived financial risk $(b=-0.178, S E=0.069, p<0.01)$. But, the influence of BRC type on perceived functional risk was not significant $(b=0.008, S E=0.070, p>0.05)$. Also, direct effect of BRC type on purchase intention was insignificant $(b=0.032, \mathrm{SE}=0.075, \mathrm{p}>0.05)$.

Meanwhile, narrative transportation significantly lowered perceived functional risk $(\mathrm{b}=-0.179, \mathrm{SE}=0.060, \mathrm{p}<0.01)$ and perceived financial risk $(\mathrm{b}=-0.127, \mathrm{SE}=0.059$, $\mathrm{p}<0.05$ ). Thus, $\mathrm{H} 2$ and $\mathrm{H} 3$ were supported respectively. But, the direct effect of narrative transportation on purchase intention was not significant $(b=0.080, \mathrm{SE}=0.063, \mathrm{p}>0.05)$. Finally, both perceived functional risk $(\mathrm{b}=-0.559, \mathrm{SE}=0.101, \mathrm{p}<0.001)$ and perceived financial risk $(b=-0.645, \mathrm{SE}=0.095, \mathrm{p}<0.001)$ had significant negative effects on purchase intention (Figure 2, Table 2).

Next, as a result of analyzing serial-parallel mediation effects, there were founded three significant mediation paths in all. The indirect effect of BRC type on purchase intention through narrative transportation and perceived functional risk was significant $(b=0.071$,

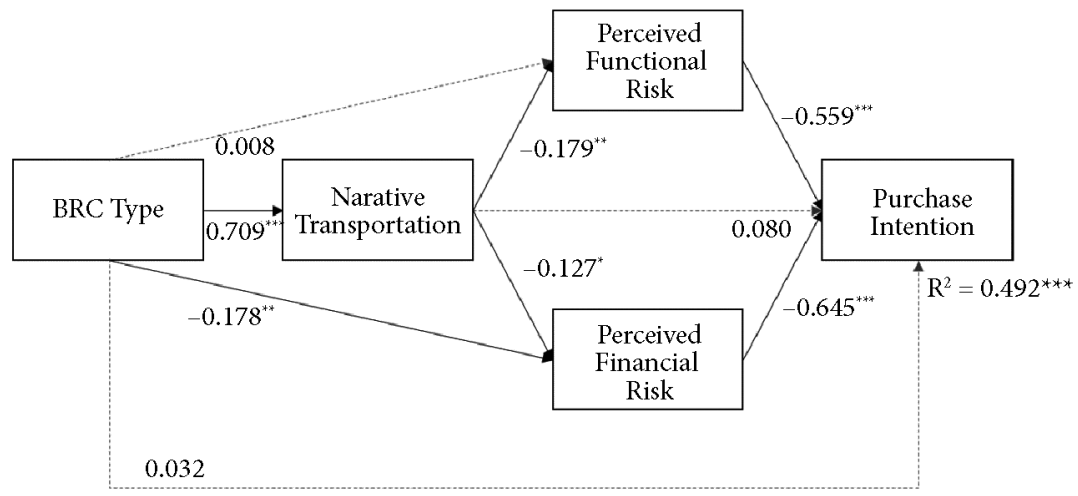

Note: The figures show the non-standardized regression coefficients. The dashed line represents nonsignificant coefficients. ${ }^{*} \mathrm{p}<0.05,{ }^{* *} \mathrm{p}<0.01,{ }^{* *} \mathrm{p}<0.001$.

Figure 2. Illustration of the direct effects for serial-parallel mediation model 
95\% $\mathrm{CI}_{\text {low }}=0.020, \mathrm{CI}_{\text {high }}=0.133$ ). Therefore, $\mathrm{H} 4$ was supported. In addition, indirect effect of BRC type on purchase intention through narrative transportation and perceived financial risk was also significant $\left(\mathrm{b}=0.058,95 \% \mathrm{CI}_{\mathrm{low}}=0.006, \mathrm{CI}_{\text {high }}=0.121\right)$, thus $\mathrm{H} 5$ confirming.

Meanwhile, the indirect effect of BRC type on purchase intention through narrative transportation was not significant $\left(\mathrm{b}=0.057,95 \% \mathrm{CI}_{\text {low }}=-0.035, \mathrm{CI}_{\text {high }}=0.146\right)$. Also, the indirect effect of BRC type on purchase intention through perceived functional risk was not significant $\left(\mathrm{b}=-0.004,95 \% \mathrm{CI}_{\text {low }}=-0.089, \mathrm{CI}_{\text {high }}=0.071\right)$. However, the indirect effect through perceived financial risk $\left(\mathrm{b}=0.115, \mathrm{CI}_{\mathrm{low}}=0.027, \mathrm{CI}_{\text {high }}=0.211\right)$ was significant (Table 2).

With the specific indirect effect contrast of the PROCESS macro, the author additionally confirmed whether there is a significant difference between the mediation paths through perceived functional risk and through perceived functional risk (indirect effect \#4 minus indirect effect \#5). No significant difference was found between the two serial-mediation paths $\left(\mathrm{b}=0.013,95 \% \mathrm{CI}_{\mathrm{low}}=-0.051, \mathrm{CI}_{\text {high }}=0.074\right)$.

Table 2. Results summary of serial-parallel mediation model

\begin{tabular}{|c|c|c|c|c|c|}
\hline \multirow{2}{*}{\multicolumn{2}{|c|}{ Path }} & \multirow{3}{*}{$\begin{array}{c}\text { Effects } \\
\text { (b) }\end{array}$} & \multirow{3}{*}{$\begin{array}{c}\begin{array}{c}\text { Boots } \\
\text { SE }\end{array} \\
0.100\end{array}$} & \multicolumn{2}{|c|}{ 95\% Bootstrap CI } \\
\hline & & & & \multirow{2}{*}{$\begin{array}{c}\text { Low } \\
0.055\end{array}$} & \multirow{2}{*}{$\begin{array}{c}\text { High } \\
0.443\end{array}$} \\
\hline $\begin{array}{l}\text { (Total Effect) } \\
\text { BRC type } \rightarrow \text { Purchase Intention }\end{array}$ & $\mathrm{C}$ & & & & \\
\hline \multicolumn{6}{|l|}{ (Direct Effect) } \\
\hline BRC type $\rightarrow$ Purchase Intention & $\mathrm{C}^{\prime}$ & 0.032 & 0.075 & -0.176 & 0.119 \\
\hline BRC type $\rightarrow$ Narrative Transportation & $\mathrm{a}_{1}$ & $0.709^{* * *}$ & 0.086 & 0.525 & 0.867 \\
\hline BRC type $\rightarrow$ Perceived Functional Risk & $\mathrm{a}_{2}$ & 0.008 & 0.070 & -0.136 & 0.139 \\
\hline BRC type $\rightarrow$ Perceived Financial Risk & $\mathrm{a}_{3}$ & $-0.178^{\star *}$ & 0.069 & -0.316 & -0.047 \\
\hline Narrative Transportation $\rightarrow$ Purchase Intention & $\mathrm{b}_{1}$ & 0.080 & 0.062 & -0.032 & 0.201 \\
\hline Perceived Functional Risk $\rightarrow$ Purchase Intention & $\mathrm{b}_{2}$ & $-0.559^{* * *}$ & 0.101 & -0.761 & -0.365 \\
\hline Perceived Financial Risk $\rightarrow$ Purchase Intention & $\mathrm{b}_{3}$ & $-0.645^{* * *}$ & 0.095 & -0.845 & -0.455 \\
\hline Narrative Transportation $\rightarrow$ Perceived Functional Risk & $\mathrm{d}_{21}$ & $-0.179^{* *}$ & 0.060 & -0.296 & -0.065 \\
\hline Narrative Transportation $\rightarrow$ Perceived Financial Risk & $d_{31}$ & $-0.127^{*}$ & 0.059 & -0.240 & -0.008 \\
\hline \multicolumn{6}{|l|}{ (Indirect Effect) } \\
\hline $\begin{array}{l}\text { (\#1) BRC Type } \rightarrow \text { Narrative Transportation } \rightarrow \\
\text { Purchase Intention }\end{array}$ & $a_{1} b_{1}$ & 0.057 & 0.045 & -0.035 & 0.146 \\
\hline $\begin{array}{l}\text { (\#2) BRC Type } \rightarrow \text { Perceived Functional Risk } \rightarrow \\
\text { Purchase Intention }\end{array}$ & $a_{2} b_{2}$ & -0.004 & 0.041 & -0.089 & 0.071 \\
\hline $\begin{array}{l}\text { (\#3) BRC Type } \rightarrow \text { Perceived Financial Risk } \rightarrow \\
\text { Purchase Intention }\end{array}$ & $a_{3} b_{3}$ & $0.115^{*}$ & 0.048 & 0.027 & 0.211 \\
\hline $\begin{array}{l}\text { (\#4) BRC Type } \rightarrow \text { Narrative Transportation } \rightarrow \\
\text { Perceived Functional Risk } \rightarrow \text { Purchase Intention }\end{array}$ & $a_{1} d_{21} b_{2}$ & $0.071^{*}$ & 0.028 & 0.020 & 0.133 \\
\hline $\begin{array}{l}\text { (\#5) BRC Type } \rightarrow \text { Narrative Transportation } \rightarrow \\
\text { Perceived Financial Risk } \rightarrow \text { Purchase Intention }\end{array}$ & $a_{1} d_{31} b_{3}$ & $0.058^{*}$ & 0.028 & 0.006 & 0.121 \\
\hline
\end{tabular}

Note: ${ }^{*} \mathrm{p}<0.05,{ }^{* *} \mathrm{p}<0.01,{ }^{* * *} \mathrm{p}<0.001, \mathrm{~b}$ : unstandardized regression coefficient, SE: standard error, CI: confidence interval. 


\section{Discussion}

Previous studies commonly emphasized that BRC is effective in lowering a potential customer's perceived purchase risk (Morgado, 2020; Terho \& Jalkala, 2017). In BRC, existing customers appear as referrers, and narrative types such as a "success story" are commonly used. This characteristic of BRC is related to the narrative transportation theory, which explains the change in attitudes, beliefs, and behavioral intention of the receivers through identification of the main character and mental simulation of the situation (Green \& Brock, 2000). Therefore, based on the narrative transportation theory, this study proposed a serial-parallel mediation model through which BRC type promotes narrative transportation, thereby lowering perceived purchase risk and, as a result, increasing purchase intention.

As the author expected, the BRC type had a significant effect on narrative transportation. This result proves that the effect of narrative transportation of marketing contents, which presented faithfully in narrative constituents and forms, appears equally in B2B marketing. In the field of B2C narrative advertising, the effectiveness of narrative has been widely proven (Kim et al., 2017), but the same effect has been confirmed in B2B purchases that place importance on rational decision-making though (Brown et al., 2011).

BRC type had a direct effect of significantly lowering perceived financial risk, but perceived functional risk was only affected by narrative transportation. Given the professional and complex nature of $\mathrm{B} 2 \mathrm{~B}$ products, functional risk may vary depending on the firm-specific characteristics of each potential customer (Nyadzayo et al., 2020). Therefore, there is possibility that the high congruency between the BRC referrer and the receiver can lead to a high narrative transportation and, consequently, a low perceived functional risk (Ruokolainen \& Aarikka-Stenroos, 2016). Kumar, Peterson, and Leone (2013) revealed that reference congruency is one of the drivers of BRC value. Considering that narrative transportation can facilitate elaborative thoughts about the product functions (Schweitzer \& Van den Hende, 2017), it is inferred that narrative transportation more pronouncedly affects the cognitive response on the product functions.

However, in terms of financial loss, since trust in suppliers is the most important factor in risk assessment (Işçi \& Kitapçi, 2020), even if receivers are not transported by the narrative, uncertainty can be lowered by understanding the relationship between buyers and sellers and purchase results. Morgado (2020) explained that BRC is the function of relationship management in that potential customers assess new suppliers by observing how they have handled prior relationships. Also, the decision-maker's trust in the supplier was enhanced by understanding the relational experience between customer and supplier without considering the congruency between them (Anaza et al., 2020).

According to the results, B2B suppliers should clarify the purpose of introducing BRC and importantly consider congruency between the referrer and target customer to enhance the narrative transportation effect. For example, if the functional risk is relevantly low due to the product being general, BRC can be developed with the goal of lowering the perceived financial risk without considering the congruency between the referrer and target customer. On the other hand, functional risk can only be lowered when receivers are narratively transported due to high congruence with the referrer. Kumar, Peterson, and Leone (2013) 
emphasized referrer-receiver congruency in BRC to promote narrative transportation. The results of this study show that the B2B suppliers should consider narrative transportation important when lowering functional risk is essential for target customers' decision-making.

This research empirically demonstrated the mechanism via which BRC types influence perceived purchase risk through narrative transportation and, in turn, affect purchase intention. BRC researchers have consistently argued that the most important benefit of BRC is to lower perceived purchase risk by eliminating uncertainty about purchasing outcomes for potential buyers (Morgado, 2020; Terho \& Jalkala, 2017). Qualitative studies have shown that narrative BRC can lower perceived purchasing risk even for start-up companies with no established customer base (Morgado, 2020; Ruokolainen \& Aarikka-Stenroos, 2016). However, there are no empirical studies on this as far as the author knows. This study sheds light on $\mathrm{BRC}$ researches in that it empirically demonstrated that the effect of BRC on purchase intention occurs through the serial-parallel mediation of narrative transportation and perceived purchase risks.

\section{Conclusions}

This study's main theoretical contribution is that it presents an integrated model explaining the effects of BRC according to narrative transportation theory and empirically demonstrated the effect paths. By providing it, the author gave a theoretical basis for explaining the underlying mechanism about reducing customers' perceived purchase risks, which has been recognized as the most significant benefit of BRC. Also, the research broadened the theoretical understanding of irrational decision-making in B2B purchasing decision research. Narrative transportation also influences the perception, belief, intention, and behavior of the receivers through emotional response, as well as cognitive responses. Therefore, BRC can also be considered as an influencing factor for irrational B2B purchasing decisions.

The results also provided timely implications for B2B marketing practitioners. B2B firms must have the capability to develop well-storied contents that can promote receivers' narrative transportation. Due to the change in the marketing environment, it is now necessary for $\mathrm{B} 2 \mathrm{~B}$ companies to secure professionals, such as writers and video producers, who can plan and produce high-quality narrative content. It is also possible to consider forming an organization dedicated to BRC marketing. It takes substantial cost and effort to engage a BRC referrer suitable for the needs of potential customers. Therefore, it is necessary to organize a dedicated BRC organization or role and to manage positive relations with existing customers who have high value as referrers. Lastly, to promote the narrative transportation of potential customers, the introduction of new technologies such as VR (virtual reality) and/or AR (augmented reality) can be considered.

Despite these implications, the current research has several limitations. Its main empirical limitation relates to the fact that it did not consider product characteristics. Since mobile enterprise application is an innovative high-tech product, the virtual product introduced in the research is appropriate for confirming viewers' risk perception. Even though further researches are required as to whether the same mechanism of narrative BRC influence appears in other products (e.g., services, commodities). In a similar vein, it is also necessary to 
confirm that there is a difference in the effect of narrative BRC on the position of the B2B supplier firms on the industrial value chain.

Analyzing the difference in the BRC effect according to buyers' purchase situation and buyer-referrer congruency is a good research topic. In this study, the author included firm size and industry of respondents as control variables, but results were not significant. However, a multigroup comparison according to distinctive factors would be a meaningful study. Lastly, it is imperative to identify the effect differentiation and mechanism when BRC is presented as rich media (e.g., video testimonial). In particular, at a time when the center of $\mathrm{B} 2 \mathrm{~B}$ marketing is moving to digital due to COVID-19, the importance of research analyzing BRC effects by using various new digital technologies is further increased.

\section{References}

Anaza, N. A., Kemp, E., Briggs, E., \& Borders, A. L. (2020). Tell me a story: The role of narrative transportation and the C-suite in B2B advertising. Industrial Marketing Management, 89, 605-618. https://doi.org/10.1016/j.indmarman.2019.02.002

Anderson, J. C., Narus, J. A., \& Van Rossum, W. (2006). Customer value propositions in business markets. Harvard Business Review, 84(3), 90. https://hbr.org/2006/03/customer-value-propositionsin-business-markets

Bagozzi, R. P., Yi, Y., \& Nassen, K. D. (1998). Representation of measurement error in marketing variables: Review of approaches and extension to three-facet designs. Journal of Econometrics, 89(1-2), 393-421. https://doi.org/10.1016/S0304-4076(98)00068-2

Bagozzi, R. P., Yi, Y., \& Phillips, L. W. (1991). Assessing construct validity in organizational research. Administrative Science Quarterly, 36(3), 421-458. https://doi.org/10.2307/2393203

Bandura, A. (1986). Social foundations of thought and action: A social cognitive theory. Prentice-Hall, Inc. https://www.worldcat.org/title/social-foundations-of-thought-and-action-a-social-cognitivetheory/oclc/12080269

Banerjee, S. C., \& Greene, K. (2012). Role of transportation in the persuasion process: Cognitive and affective responses to antidrug narratives. Journal of Health Communication, 17(5), 564-581. https://doi.org/10.1080/10810730.2011.635779

Behling, O., \& Law, K. S. (2000). Translating questionnaires and other research instruments: Problems and solutions (Vol. 133). Sage Publications, Inc. https://doi.org/10.4135/9781412986373

Bonnin, G., \& Alfonso, M. R. (2019). The narrative strategies of B2B technology brands. Journal of Business \& Industrial Marketing, 34(7), 1448-1458. https://doi.org/10.1108/JBIM-03-2019-0112

Brown, B. P., Bellenger, D. N., \& Johnston, W. J. (2007). The implications of business-to-business and consumer market differences for B2B branding strategy. Journal of Business Market Management, 1, 209-230. https://doi.org/10.1007/s12087-007-0011-x

Brown, B. P., Zablah, A. R., Bellenger, D. N., \& Johnston, W. J. (2011). When do B2B brands influence the decision making of organizational buyers? An examination of the relationship between purchase risk and brand sensitivity. International Journal of Marketing Research, 28(3), 194-204. https://doi.org/10.1016/j.ijresmar.2011.03.004

Cacioppo, J. T., \& Petty, R. E. (1984). The Elaboration Likelihood Model of persuasion. Advances in Experimental Social Psychology, 19(1), 123-205. https://doi.org/10.1016/S0065-2601(08)60214-2

Chaiken, S. (1980). Heuristic versus systematic information processing and the use of source versus message cues in persuasion. Journal of Personality and Social Psychology, 39(5), 752-766.

https://doi.org/10.1037/0022-3514.39.5.752 
Deighton, J., Romer, D., \& McQueen, J. (1989). Using drama to persuade. Journal of Consumer Research, 16(3), 335-343. https://doi.org/10.1086/209219

Escalas, J. E., Moore, M. C., \& Britton, J. E. (2004). Fishing for feeling? Hooking viewers helps! Journal of Consumer Psychology, 14(1-2), 105-114.

Featherman, M. S., \& Pavlou, P. A. (2003). Predicting e-services adoption: A perceived risk facets perspective. International Journal of Human-Computer Studies, 59(4), 451-474. https://doi.org/10.1016/S1071-5819(03)00111-3

Feng, Y. (2018). Facilitator or inhibitor? The use of 360-degree videos for immersive brand storytelling. Journal of Interactive Advertising, 18(1), 28-42. https://doi.org/10.1080/15252019.2018.1446199

Fitzgerald, K., \& Green, M. C. (2017). Narrative persuasion: Effects of transporting stories on attitudes, beliefs, and behaviors. In F. Hakemulder, M. M. Kuijpers, Ed S. Tan, K. Bálint, \& M. M. Doicaru (Eds.), Narrative absorption (pp. 49-67). John Benjamins Publishing Company. https://doi.org/10.1075/lal.27.04fit

Gilliam, D. A., \& Flaherty, K. E. (2015). Storytelling by the sales force and its effect on buyer-seller exchange. Industrial Marketing Management, 46, 132-142. https://doi.org/10.1016/j.indmarman.2015.01.013

Green, M. C., \& Brock, T. C. (2000). The role of transportation in the persuasiveness of public narratives. Journal of Personality and Social Psychology, 79(5), 701-721. https://doi.org/10.1037//0022-3514.79.5.701

Green, M. C., \& Fitzgerald, K. (2017). Transportation theory applied to health and risk messaging. In Oxford research encyclopedia of communication. https://doi.org/10.1093/acrefore/9780190228613.013.261

Green, M. C., \& Sestir, M. (2017). International encyclopedia of media effects. Wiley.

Grewal, D., Gotlieb, J., \& Marmorstein, H. (1994). The moderating effects of message framing and source credibility on the price-perceived risk relationship. Journal of Consumer Research, 21(1), 145-153. https://doi.org/10.1086/209388

Ha, H.-Y. (2002). The effects of consumer risk perception on pre-purchase information in online auctions: Brand, word-of-mouth, and customized information. Journal of Computer-Mediated Communication, 8(1). https://doi.org/10.1111/j.1083-6101.2002.tb00160.x

Hair, J. F., Risher, J. J., Sarstedt, M., \& Ringle, C. M. (2019). When to use and how to report the results of PLS-SEM. European Business Review, 31(1), 2-24. https://doi.org/10.1108/EBR-11-2018-0203

Harrison, L., Gavin, R., Plotkin, C. L., \& Stanley, J. (2020, July). How B2B sales have changed during COVID-19. McKinsey Quarterly. https://www.mckinsey.com/business-functions/marketing-andsales/our-insights/how-b2b-sales-have-changed-during-covid-19

Hayes, A. F. (2018). Partial, conditional, and moderated moderated mediation: Quantification, inference, and interpretation. Communication Monographs, 85(1), 4-40. https://doi.org/10.1080/03637751.2017.1352100

Horton, R. L. (1976). The structure of perceived risk: Some further progress. Journal of the Academy of Marketing Science, 4, 694-706. https://doi.org/10.1177/009207037600400303

Igartua, J. J., \& Rodríguez-Contreras, L. (2020). Narrative voice matters! Improving smoking prevention with testimonial messages through identification and cognitive processes. International Journal of Environmental Research and Public Health, 17(19), 7281. https://doi.org/10.3390/ijerph17197281

Işçi, Ü., \& Kitapçi, H. (2020). Responses of Turkish consumers to product risk information in the context of negative eWOM. Journal of Business Economics and Management, 21(6), 1593-1609. https://doi.org/10.3846/jbem.2020.13383

Jaakkola, E., \& Aarikka-Stenroos, L. (2019). Customer referencing as business actor engagement behavior - Creating value in and beyond triadic settings. Industrial Marketing Management, 80(1), 27-42. https://doi.org/10.1016/j.indmarman.2018.06.014 
Jalkala, A., \& Salminen, R. T. (2009). Communicating customer references on industrial companies' Web sites. Industrial Marketing Management, 38(7), 825-837. https://doi.org/10.1016/j.indmarman.2008.04.009

Jalkala, A., \& Salminen, R. T. (2010). Practices and functions of customer reference marketing - Leveraging customer references as marketing assets. Industrial Marketing Management, 39(6), 975-985. https://doi.org/10.1016/j.indmarman.2010.06.017

Kang, J. A., Hong, S., \& Hubbard, G. T. (2020). The role of storytelling in advertising: Consumer emotion, narrative engagement level, and word-of-mouth intention. Journal of Consumer Behaviour, 19(1), 47-56. https://doi.org/10.1002/cb.1793

Kardes, F. R., Herr, P. M., \& Schwarz, N. (2019). Handbook of research methods in consumer psychology ( $1^{\text {st }}$ ed.). Routledge. https://doi.org/10.4324/9781351137713

Kelley, K. (2007). Methods for the behavioral, educational, and social sciences: An R package. Behavior Research Methods, 39(4), 979-984. https://doi.org/10.3758/BF03192993

Kim, E., Ratneshwar, S., \& Thorson, E. (2017). Why narrative Ads work: An integrated process explanation. Journal of Advertising, 46(2), 283-296. https://doi.org/10.1080/00913367.2016.1268984

Krakow, M. M., Yale, R. N., Jensen, J. D., Carcioppolo, N., \& Ratcliff, C. L. (2018). Comparing mediational pathways for narrative-and argument-based messages: Believability, counterarguing, and emotional reaction. Human Communication Research, 44(3), 299-321. https://doi.org/10.1093/hcr/hqy002

Kumar, V., Petersen, J. A., \& Leone, R. P. (2013). Defining, measuring, and managing business reference value. Journal of Marketing, 77(1), 68-86. https://doi.org/10.1509/jm.11.0424

Lakens, D. (2013). Calculating and reporting effect sizes to facilitate cumulative science: A practical primer for $t$-tests and ANOVAs. Frontiers in Psychology, 4, 863. https://doi.org/10.3389/fpsyg.2013.00863

Lamberton, C., \& Stephen, A. T. (2016). A thematic exploration of digital, social media, and mobile marketing: Research evolution from 2000 to 2015 and an agenda for future inquiry. Journal of Marketing, 80(6), 146-172. https://doi.org/10.1509/jm.15.0415

Lee, H. G., Jung, C. M., \& Kim, Y. C. (2017). An exploratory study on the effects of B2B marketing content strategy on the intention to accept product. Proceedings of Korea Distribution Association, Korea. http://www.dbpia.co.kr/journal/articleDetail?nodeId=NODE07230016

Leiner, D. J. (2016). Our research's breadth lives on convenience samples A case study of the online respondent pool "SoSci Panel". SCM Studies in Communication and Media, 5(4), 367-396. https://doi.org/10.5771/2192-4007-2016-4-367

Lien, N. H., \& Chen, Y. L. (2013). Narrative ads: The effect of argument strength and story format. Journal of Business Research, 66(4), 516-522. https://doi.org/10.1016/j.jbusres.2011.12.016

Lippel, K., \& Quinlan, M. (2011). Regulation of psychosocial risk factors at work: An international overview. Safety Science, 49(4), 543-546. https://doi.org/10.1016/j.ssci.2010.09.015

Mar, R. A. (2018). Stories and the promotion of social cognition. Current Directions in Psychological Science, 27(4), 257-262. https://doi.org/10.1177/0963721417749654

Mitchell, V. W. (1992). Understanding consumers' behaviour: Can perceived risk theory help? Management Decision, 30(3). https://doi.org/10.1108/00251749210013050

Morgado, A. V. (2020). How to profit from reference marketing in B2B market. The European Business Review. https://www.europeanbusinessreview.com/how-to-profit-from-reference-marketingin-b2b-markets/

Mumper, M. L., \& Gerrig, R. J. (2017). Leisure reading and social cognition: A meta-analysis. Psychology of Aesthetics, Creativity, and the Arts, 11(1), 109-120. https://doi.org/10.1037/aca0000089 
Nyadzayo, M. W., Casidy, R., \& Thaichon, P. (2020). B2B purchase engagement: Examining the key drivers and outcomes in professional services. Industrial Marketing Management, 85, 197-208. https://doi.org/10.1016/j.indmarman.2019.11.007

Paluch, S., \& Wunderlich, V. N. (2016). Contrasting risk perceptions of technology-based service innovations in inter-organizational settings. Journal of Business Research, 69(7), 2424-2431. https://doi.org/10.1016/j.jbusres.2016.01.012

Peter, J. P., \& Ryan, M. J. (1976). An investigation of perceived risk at the brand level. Journal of Marketing Research, 13(2), 184-188. https://doi.org/10.1177/002224377601300210

Podsakoff, P. M., MacKenzie, S. B., \& Podsakoff, N. P. (2012). Sources of method bias in social science research and recommendations on how to control it. Annual Review of Psychology, 63, 539-569. https://doi.org/10.1146/annurev-psych-120710-100452

Raymond, J. L., \& Medina, J. F. (2018). Computational principles of supervised learning in the cerebellum. Annual Review of Neuroscience, 41, 233-253. https://doi.org/10.1146/annurev-neuro-080317-061948

Ruokolainen, J., \& Aarikka-Stenroos, L. (2016). Rhetoric in customer referencing: Fortifying sales arguments in two start-up companies. Industrial Marketing Management, 54, 188-202. https://doi.org/10.1016/j.indmarman.2015.08.002

Salminen, R., \& Möller, K. (2006). Role of references in business marketing - Towards a normative theory of referencing. Journal of Business-to-Business Marketing, 13(1), 1-51. https://doi.org/10.1300/J033v13n01_01

Schweitzer, F., \& Van den Hende, E. A. (2017). Drivers and consequences of narrative transportation: Understanding the role of stories and domain-specific skills in improving radically new products. Journal of Product Innovation Management, 34(1), 101-118. https://doi.org/10.1111/jpim.12329

Seo, Y., Li, X., Choi, Y. K., \& Yoon, S. (2018). Narrative transportation and paratextual features of social media in viral advertising. Journal of Marketing, 47(1), 83-95. https://doi.org/10.1080/00913367.2017.1405752

Sharma, P. (2020). Why are industrial firms high or low brand sensitive? An empirical investigation. Journal of Marketing Theory and Practice, 28(1), 56-78. https://doi.org/10.1080/10696679.2019.1662314

Sharma, P., Sengupta, R. N., \& Lichtenthal, J. D. (2020). Facets of business-to-business brand equity: Mixed-methods approach. Marketing Intelligence \& Planning, 37(7), 754-769. https://doi.org/10.1108/MIP-10-2018-0437

Su, P. J., Lu, H. P., \& Lin, P. H. (2018). How the microfilm marketing strategy stimulates consumers' purchase intention. Social Behavior and Personality: An International Journal, 46(6), 953-968. https://doi.org/10.2224/sbp.6943

Teng, L., Laroche, M., \& Zhu, H. (2007). The effects of multiple-ads and multiple-brands on consumer attitude and purchase behavior. Journal of Consumer Marketing, 24(1), 27-35. https://doi.org/10.1108/07363760710720966

Terho, H., \& Jalkala, A. (2017). Customer reference marketing: Conceptualization, measurement and link to selling performance. Industrial Marketing Management, 64, 175-186. https://doi.org/10.1016/j.indmarman.2017.01.005

Tojib, D. R., \& Sugianto, L. F. (2006). Content validity of instruments in IS research. Journal of Information Technology Theory and Application (JITTA), 8(3), 5. https://aisel.aisnet.org/jitta/vol8/iss3/5

Van Laer, T., de Ruyter, K., Visconti, L. M., \& Wetzels, M. (2014). The extended transportation-imagery model: A meta-analysis of the antecedents and consequences of consumers' narrative transportation. Journal of Consumer Research, 40(5), 797-817. https://doi.org/10.1086/673383

Van Laer, T., Feiereisen, S., \& Visconti, L. M. (2019). Storytelling in the digital era: A meta-analysis of relevant moderators of the narrative transportation effect. Journal of Business Research, 96(1), 135-146. https://doi.org/10.1016/j.jbusres.2018.10.053 


\section{APPENDIX}

Narrative BRC stimuli

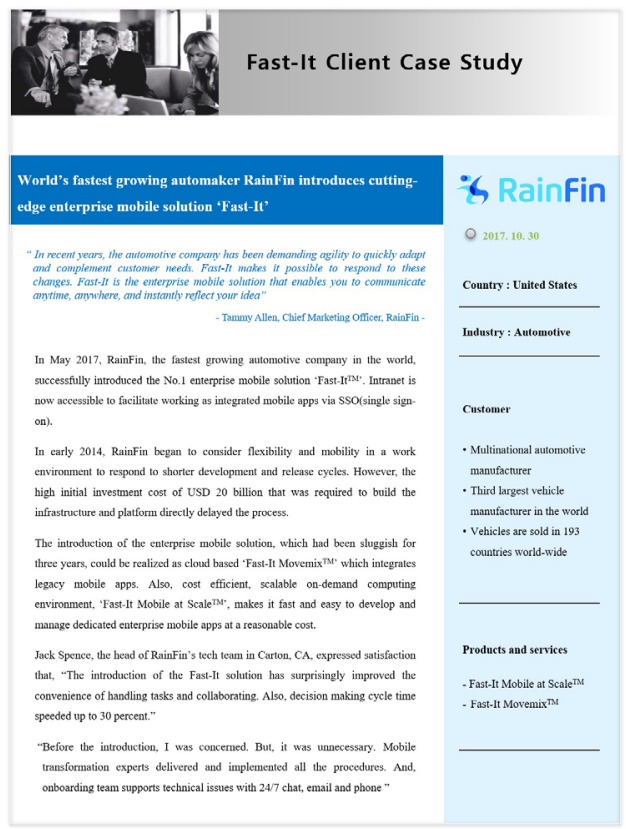

Non-narrative BRC stimuli

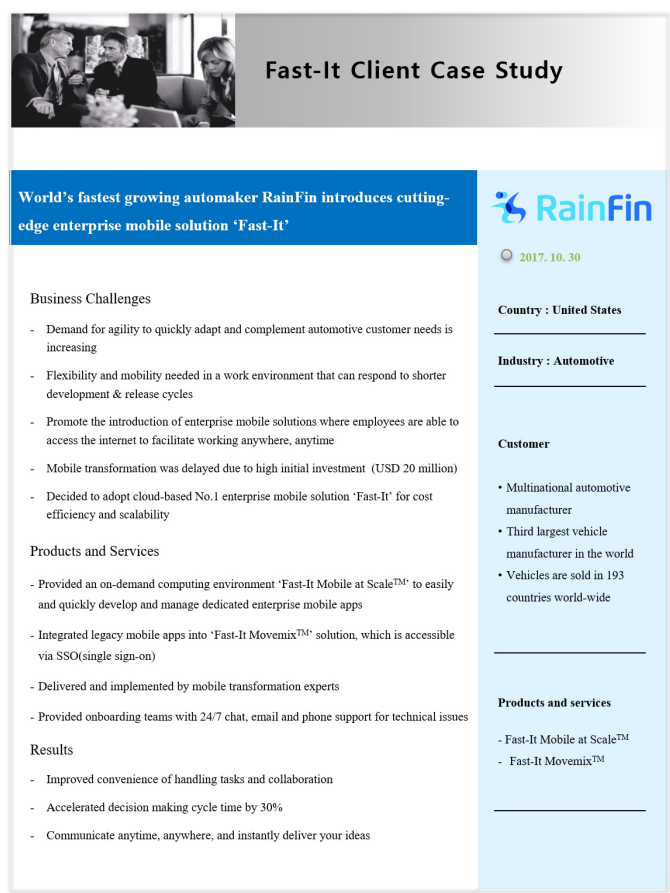

